7-22-2016

\title{
Putting Spearman's Hypothesis to Work: Job IQ as a Predictor of Employee Racial Composition
}

\author{
Bryan J. Pesta \\ b.pesta@csuohio.edu \\ Peter Poznanski \\ Cleveland State University, p.poznanski@csuohio.edu
}

Follow this and additional works at: https://engagedscholarship.csuohio.edu/bus_facpub

Part of the Cognitive Psychology Commons, and the Industrial and Organizational Psychology

Commons

How does access to this work benefit you? Let us know!

Publisher's Statement

Copyright 2016, the authors. Published in Open Differential Psychology by OpenPsych, www.openpsych.net

\section{Original Published Citation}

Pesta, B. \& Poznanski, P. (2016). Putting Spearman's hypothesis to work: Job IQ as a predictor of employee racial composition. Open Differential Psychology, retrieved from http://openpsych.net/ODP/ 2016/07/putting-spearmans-hypothesis-to-work-job-iq-as-a-predictor-of-employee-racial-composition/

This Article is brought to you for free and open access by the Monte Ahuja College of Business at EngagedScholarship@CSU. It has been accepted for inclusion in Business Faculty Publications by an authorized administrator of EngagedScholarship@CSU. For more information, please contact library.es@csuohio.edu. 
Submitted: $\quad 23^{\text {rd }}$ of May 2016

Published: $\quad 22^{\text {nd }}$ of July 2016

\title{
Putting Spearman's Hypothesis to Work: Job IQ as a Predictor of Employee Racial Composition
}

\author{
Bryan J. Pesta $\quad$ Peter J. Poznanski ${ }^{\dagger}$
}

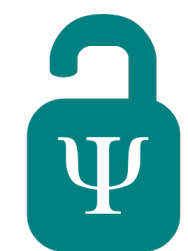

Open Differential

Psychology

\begin{abstract}
Job complexity and employee intelligence covary strongly. Likewise, race differences exist on mean IQ / g scores. Spearman's hypothesis predicts that race differences on cognitive tests are mainly g differences, and that the former should covary with how well mental tests measure the latter. Here we use jobs as "mental tests," and predict that as job IQ increases, the percent of White and Asian workers will increase, while the percent of Black workers will decrease. We found moderate to strong support for Spearman's hypothesis across these three racial groups. We also found a very large correlation (.86) between job IQ and complexity, as measured by the U.S. Federal Government's Dictionary of Occupational Titles classification scheme. In sum, like different mental tests, different jobs are more or less g-loaded. And, consistent with Spearman's hypothesis, the g-loading of a job predicts its demographic composition.
\end{abstract}

Keywords: Job, IQ, race differences, intelligence

\section{Putting Spearman's Hypothesis to Work: Job IQ as a Predictor of Employee Racial Composition}

Scores on diverse sets of mental abilities tests correlate positively (see, e.g., Carroll 1997). Spearman (1904, 1927) termed this the "positive manifold," and postulated the existence of a latent trait, g, as its explanation. Statistically, g is (usually) measured as the first, un-rotated factor emerging from analysis of an assorted set of mental abilities tests. For example, g might be the variance common to solving a math problem, defining a word, and reading a map. Biologically, g likely reflects the speed and efficiency with which brains process information (Jensen 1998, 2011; Pesta \& Poznanski 2008). Psychologically, $\mathrm{g}$ is problem solving ability, and usually fares as the best predictor of important educational, organizational, and psychological outcomes (Gottfredson 2002, 2003; Neisser et al. 1996; Schmidt \& Hunter 1998, 2004).

Race groups differ in mean IQ scores (Neisser et al. 1996; Roth et al. 2001; Rushton \& Jensen 2005).

\footnotetext{
${ }^{*}$ Correspondence concerning this article should be addressed to Bryan J. Pesta, Cleveland State University, Department of Management, 2121 Euclid Avenue, Cleveland OH 44115, E-mail: b.pesta@csuohio.edu

${ }^{\dagger}$ Cleveland State University
}

Over 100 years of data exist on Black / White differences on IQ in the USA (see, e.g., Roth et al. 2001). Last century, for example, a task force commissioned by the American Psychological Association reviewed the literature to date, and concluded that that the Black / White difference is approximately one standard deviation (Neisser et al. 1996). This century, Roth et al. (2001) conducted a massive, meta-analytic summary of race / IQ differences ( $\mathrm{N}$ $=6,246,729$ people). They reported an overall Black / White effect size of 1.10.

Other racial and ethnic groups show different mean IQs. The Asian American IQ mean is estimated at 106 (Rushton \& Jensen 2005). Hispanic Americans, whether considered a race or an ethnicity, average at least one-half a standard deviation below Whites (Neisser et al. 1996; Roth et al. 2001; Rushton \& Jensen 2005). Moreover, Lynn and colleagues (Lynn \& Vanhanen 2002; Lynn \& Meisenberg 2010) have calculated IQs for hundreds of nations across the world. National IQs vary widely, yet are consistent with effects seen using individuals of different races, and predict important economic, educational, and psychological outcomes (for a review, see, Lynn \& Vanhanen 2012).

A parsimonious explanation for race / IQ differences is Spearman's hypothesis (Spearman 1927; see also, Jensen 1985). It proposes that IQ differ- 
ences are mainly g differences. Spearman's hypothesis predicts that Black / White differences (e.g.) should be highest on tests most heavily saturated with g. Jensen (1985) invented the method of correlated vectors to test Spearman's hypothesis. The premise is that if race differences are g differences, then they should co-vary with the g-loadings of mental abilities tests. That is, the more a mental task measures $g$, the larger the race difference it should produce. The literature strongly supports Spearman's hypothesis (for reviews, see, e.g., Dolan 2000; Jensen 1998; Rushton \& Jensen 2005.

Jobs-like individuals, races and nations_-can be assigned different IQ scores. Examples of occupations with different mean IQs include custodian (94), typist (102), nurse (111), and computer programmer (115). These values assume $\mathrm{M}=100$ and $\mathrm{SD}=15$, and come from the Wonderlic Personnel Test \& Scholastic Level Exam User's Manual (2002). Hence, custodians are roughly half a standard deviation below average, whereas, programmers are a standard deviation above.

Job complexity and IQ are intrinsically linked as demonstrated by a large literature (Hunter \& Hunter 1984; Gottfredson 1986, 2002; Roth et al. 2001). Consistent with this literature, the U.S. federal government has classified thousands of jobs based on the relative complexity required to work them. Results of these classifications appear in the "Dictionary of Occupational Titles" (DOT; U.S. Bureau of Labor Statistics 1991). DOT codes indicate job complexity on three different elements of possible worker activity. The elements include dealing with data, people, and things ${ }^{1}$. Hence, each job is a three-digit DOT code that designates its value on each of the three job elements.

Lower scores on a DOT element indicate higher complexity and / or status. Accountants, for example, score one ("synthesizing") on data. They score six ("speaking-signaling") on people, and two ("operating-controlling") on things. Thus, the DOT code for Accountant is 162. In contrast, Executives score one on people ("mentoring"), and Machinists score one on things ("setting up"). Likewise, Maid / Matrons score eight ("taking instructions") on people, and Writers score seven ("handling") on things.

Tying together IQ, race, and job complexity, we return to the method of correlated vectors. We argue that a job is analogous to a mental test. Different jobs require different IQs (i.e., levels of $g$ ) to perform successfully. A novel test of Spearman's hypothesis is to use the IQ of various jobs as predictors of the racial composition of their employees. If Spearman's hypothesis is correct, as job IQ

\footnotetext{
${ }^{1}$ For complete descriptions of the job elements, see http: //www.occupationalinfo.org/appendxb_1.html.
}

increases, the percentage of Black workers holding the job should decrease (but the percentage of White and Asian workers should increase). The opposite is predicted as job IQ decreases.

The present study therefore tests Spearman's hypothesis using jobs as a g-loaded vector, and percent racial composition as the outcome measure. Finally, we also predict a significant correlation between job IQ and Data values on the DOT, given that job complexity, IQ and data processing all seem related. In fact, this is the essence of Spearman's hypothesis: The more cognitively complex a mental test (or job, in this case), the more it should both load on $\mathrm{g}$, and produce group differences. We make no a priori predictions about job IQ's correlation with either People or Things.

\section{Method}

The Wonderlic Personnel Test \& Scholastic Level Exam User's Manual (2002) lists IQ scores and DOT codes for 145 different jobs. We increased this number to 147 by separating truck from bus drivers, and medical from dental assistants. We did this because the technical manual used to derive demographic data listed these as distinct jobs. This technical manual is an annual publication from the Bureau of Labor Statistics (BLS), entitled: "'Labor Force Characteristics by Race and Ethnicity" (U.S. Bureau of Labor Statistics 2015). It reports the most recent percent White, Black, Asian and Hispanic workers within each "detailed occupation" in the U.S. labor force. We coded all but percent-Hispanic, as the BLS considers this group to be an ethnicity versus a race. That is, people in the BLS' Hispanic category could be either White, Black or neither race. We also coded the identical data set for the year 2012 (U.S. Bureau of Labor Statistics 2013). We did this to cross-validate results found with the 2014 data, and to test whether the demographic content of different jobs is stable across years.

Coding involved simply matching job titles from the Wonderlic to those in the BLS. This process, however, was occasionally problematic. For example, the BLS sometimes lumped together jobs that the Wonderlic considered separate (e.g., accountant and auditor). At other times, the opposite occurred. The Wonderlic, for example, considered insurance claims adjusters and insurance examiners as separate jobs, but the BLS lumped them together.

We therefore adopted a rule that if a Wonderlic job title appeared in the BLS manual, we coded demographic information for that job. Further, both authors coded all jobs separately. Discrepancies were discussed, and consenus was reached for each job. The end result, however, was that 23 (16\%) 
jobs in the Wonderlic manual had no match in the BLS technical report. This was partly because some Wonderlic jobs titles were too specific (e.g., bagger, meter reader, roustabout). For these jobs, the BLS either did not include the job title, or included it but reported no data (i.e., the BLS did not report ethnicity data on jobs with less than 50,000 employees).

The converse problem existed as well. Some Wonderlic job titles were too general (e.g., installer, unskilled laborer, general office) to match a "detailed occupation" in the BLS data set. Despite these occasional problems, the final data set contained IQs, ethnicity, and DOT values for 124 (85\%) different Wonderlic jobs. The ethnicity values were for the year 2014 (most recent) and the year 2012 (used for cross validation).

\section{Results}

Table 1 shows means, standard deviations, and ranges for all variables. Although the effect is small, the mean IQ of all jobs, 104.5, is higher than the population IQ mean of 100 for individuals. We speculate this is because there are not many jobs with considerably low IQ requirements. That is, few jobs exist where the minimum IQ is in the $10^{\text {th }}$ or $15^{\text {th }}$ percentile. Consistent with this is the fact that the lower one's IQ, the less likely he or she is to be in the labor force (see, e.g., Gottfredson 2003; Herrnstein \& Murray 1994). At any rate, the mean value of 104.5 represents the population parameter for all jobs listed by Wonderlic (2002).

Table 1: Descriptive Statistics for the Study Variables.

\begin{tabular}{lrrrr}
\hline Variable & Mean & SD & Min & Max \\
\hline Job IQ & 104.5 & 7.6 & 89 & 119 \\
\% White, 2014 & 80.0 & 7.3 & 56.7 & 93.4 \\
\% Black, 2014 & 11.6 & 6.2 & 2.8 & 35.9 \\
\% Asian, 2014 & 5.6 & 3.8 & 0.0 & 21.4 \\
\hline Data & 3.03 & 1.9 & 0 & 6 \\
\hline People & 6.1 & 1.9 & 0 & 8 \\
Things & 4.6 & 2.5 & 0 & 7 \\
\% White, 2012 & 81.2 & 6.6 & 57.4 & 92.7 \\
\% Black, 2012 & 11.1 & 5.7 & 1.60 & 34.5 \\
\% Asian, 2012 & 5.0 & 3.5 & 0.3 & 17.3 \\
\hline
\end{tabular}

Note: $\mathrm{N}=124$ for the race variables, and 147 for all other variables.

In contrast, the ethnicity data by job mirror almost perfectly the ethnic diversity of the American labor force. According to the U.S. Bureau of Labor Statistics (2015), $79 \%$ of people in the U.S labor force are White, $12 \%$ are Black, and $6 \%$ are Asian. The Table 1 mean values by job are nearly identical to the values for the entire U.S. labor force.
Table 2 is a correlation matrix of the key study variables. Support exists for Spearman's hypothesis in that the racial composition of a job can indeed be predicted from the job's IQ. Specifically, job IQ correlates $.47,-.60$, and .23 with the percentage of workers who are White, Black, and Asian, respectively. These effect sizes can be characterized as moderate, large, and small, respectively. As a cross check on validity, we correlated these same variables, but used the 2012 BLS data. The correlations were $.46,-.57$, and .20 respectively. Also, the 2012 and 2014 BLS data show strong stability in the demographics of jobs over two-years. The correlations across 2012 and 2014 were $.88, .87$ and .87 for percent White, Black, and Asian, respectfully.

A remarkably strong correlation exists in Table 2 between job IQ and the Data element from the DOT (-.86; see also Figure 1). This finding is not new. The relationship between complexity and IQ is welldocumented, as cited above. The magnitude of the effect, however, is surprising as the Wonderlic manual and the BLS technical report do not share common method variance. Also from Table 2, the DOT People element predicts job IQ strongly, -.55; whereas, the Things element does not, .06. In sum, the DOT captures job complexity well—especially the data element-and job complexity correlates very strongly with job IQ.

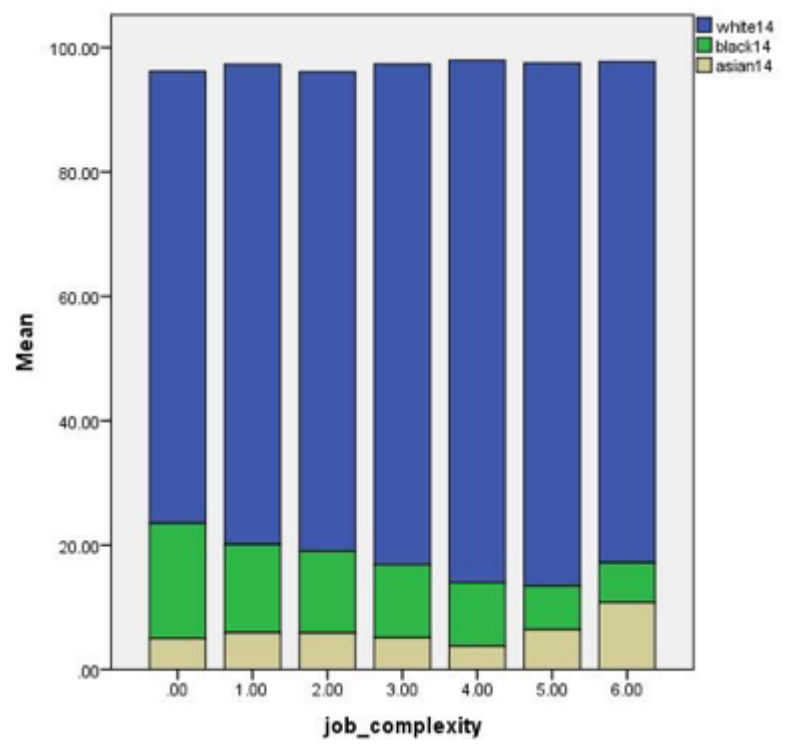

Figure 1: Percent racial composition by job complexity (i.e., DOT Data values).

A reviewer recommended we explore further the relatively weak correlation between percent Asian and IQ. We therefore conducted multiple regression analyses (post facto) to see whether values on either people or things ${ }^{2}$ change (i.e., suppress) the

\footnotetext{
${ }^{2}$ We excluded values on Data given the very large correlation $(-.86)$ between it and job IQ.
} 
Table 2: Correlations between Job IQ, Racial Composition, and DOT Codes

\begin{tabular}{lrrrrrrr}
\hline & Job IQ & \% White & \% Black & \% Asian & Data & People & Things \\
\hline Job IQ & - & .47 & -.60 & .23 & -.86 & -.55 & .06 \\
\% White & & - & -.85 & -.39 & -.51 & -.38 & -.03 \\
\% Black & & & - & -.12 & .65 & .32 & .09 \\
\% Asian & & & & - & -.22 & .13 & -.07 \\
Data & & & & - & .51 & -.04 \\
People & & & & & & - & -.27 \\
Things & & & & & & - \\
\hline
\end{tabular}

Table 3: IQ, People and Things as Predictors of a Job's Ethnic Composition

\begin{tabular}{lccccc}
\hline Ethnicity & Variable & Beta & SE Beta & Lower CI & Upper CI \\
\hline White \% & IQ & .39 & .09 & .20 & .57 \\
& People & -.19 & .10 & -.37 & .00 \\
& Things & -.09 & .08 & -.26 & .07 \\
\hline Black \% & & & & & \\
& IQ & -.60 & .09 & -.77 & -.43 \\
& People & .02 & .09 & -.16 & .19 \\
& Things & .12 & .07 & -.03 & .26 \\
& & & & & \\
Asian \% & & & & & \\
& IQ & .41 & .10 & .21 & .61 \\
& People & .34 & .10 & .14 & .55 \\
& Things & .00 & .09 & -.17 & .17 \\
\hline
\end{tabular}

Note: $\mathrm{R}^{2}$ values are $.26, .38$, and .14 for Whites, Blacks, and Asians, respectively.

relationship between ethnicity and job IQ. Also, to increase the stability of our results, we averaged percent White, Black, and Asian across the 2012 and 2014 values. Results of the regression analyses appear in Table 3.

Predicting percent White from Job IQ, People, and Things produced beta weights of .39, -.19, and -.09, respectfully. The same analysis predicting percent Black produced beta weights of $-.60, .02$, and .12, respectfully. The DOT elements failed to predict the percentage of Whites or Blacks in different jobs (with IQ in the equations). However, this analysis on percent Asian produced beta weights of .41 (IQ), .34 (People), and .00 (Things). Thus, values on People suppress the true relationship between Job IQ and percent Asian.

\section{Discussion and conclusion}

We proposed the following causal links: IQ tests measure g. Ethnic groups differ on mean levels of IQ. Spearman's hypothesis suggests that IQ differences are mainly g differences. The method of correlated vectors is used to test Spearman's hypoth- esis. It tests whether group differences covary with the g loadings of mental ability tests. We suggested that jobs are like mental tests, in that different jobs require different g-levels to perform successfully. Hence, we predicted that the racial composition of a job should be predicted by the job's IQ.

We found consistent support for this hypothesis. As job IQ increased, the percent of Black workers decreased, but the percent of White and Asian workers increased. Although the correlation was small for Asians (due to suppression via values on People), it was non-trivial for Whites, and large for Blacks. Spearman's hypothesis is therefore supported in a novel way.

Consistent with past research (Gottfredson 1986, 2003; Schmidt \& Hunter 2004), we found that job complexity and IQ are strongly related. The DOT element, Data, correlated very strongly with job IQs as reported by the Wonderlic (2002, albeit these are aggregate / ecological correlations). The People (but not Things) element was also a non-trivial predictor of job IQ. Again, job complexity and IQ are intrinsically linked.

Limitations to the present study include that we 
did not match $100 \%$ of the jobs in the Wonderlic manual to those reported by the BLS. Also, we lacked data on a significant segment of the U.S. labor force-Hispanics-due to the way in which the U.S. federal government defines and tracks this group of people. Finally, we assumed throughout that job IQ is a good (but imperfect) proxy for $\mathrm{g}$. We nonetheless believe the data presented here support Spearman's hypothesis in a distinct way: The racial composition of a job can indeed be predicted by its IQ.

\section{References}

Carroll, J. B. The three-stratum theory of cognitive abilities. New York, NY: Guilford Press, 1997.

Dolan, C. V. Investigating spearman's hypothesis by means of multi-group confirmatory factor analysis. Multivariate Behavioral Research, 35(1):21-50, 2000.

Gottfredson, L. S. Occupational aptitude patterns map: Development and implications for a theory of job aptitude requirements. Journal of Vocational Behavior, 29(2):254-291, 1986.

Gottfredson, L. S. g: Highly general and highly practical. The general factor of intelligence: How general is it, pages 331-380, 2002.

Gottfredson, L. S. The scientific study of general intelligence: Tribute to Arthur Jensen. New York: Pergamon, 2003. ISBN 0-08-043793-1.

Herrnstein, R. J. \& Murray, C. The Bell curve: Intelligence and class structure in American life. New York, NY: Free Press Paperbacks, 1994. ISBN 0-02-914673-9.

Hunter, J. E. \& Hunter, R. F. Validity and utility of alternative predictors of job performance. Psychological bulletin, 96(1):72-98, 1984.

Jensen, A. R. The nature of the black-white difference on various psychometric tests: Spearman's hypothesis. Behavioral and Brain Sciences, 8(2): 193-263, 1985.

Jensen, A. R. The g factor. Westport, Connecticut: Praeger, 1998.

Jensen, A. R. The theory of intelligence and its measurement. Intelligence, 39(4):171-177, 2011.

Lynn, R. \& Meisenberg, G. National IQs calculated and validated for 108 nations. Intelligence, 38(4): 353-360, 2010.

Lynn, R. \& Vanhanen, T. IQ and the wealth of nations. Westport, Connecticut: Praeger, 2002. ISBN 0275-97510-X.
Lynn, R. \& Vanhanen, T. National IQs: A review of their educational, cognitive, economic, political, demographic, sociological, epidemiological, geographic and climatic correlates. Intelligence, 40 (2):226-234, 2012.

Neisser, U., Boodoo, G., Bouchard Jr, T. J., Boykin, A. W., Brody, N., Ceci, S. J., Halpern, D. F., Loehlin, J. C., Perloff, R., Sternberg, R. J., \& Urbina, S. Intelligence: knowns and unknowns. American psychologist, 51(2):77-101, 1996.

Pesta, B. J. \& Poznanski, P. J. Black-white differences on IQ and grades: The mediating role of elementary cognitive tasks. Intelligence, 36(4): 323-329, 2008.

Roth, P. L., Bevier, C. A., Bobko, P., Switzer, F. S., \& Tyler, P. Ethnic group differences in cognitive ability in employment and educational settings: A meta-analysis. Personnel Psychology, 54(2):297330, 2001.

Rushton, J. P. \& Jensen, A. R. Thirty years of research on race differences in cognitive ability. Psychology, public policy, and law, 11(2):235-294, 2005.

Schmidt, F. L. \& Hunter, J. E. The validity and utility of selection methods in personnel psychology: Practical and theoretical implications of 85 years of research findings. Psychological bulletin, 124 (2):262-274, 1998.

Schmidt, F. L. \& Hunter, J. E. General mental ability in the world of work: Occupational attainment and job performance. Journal of personality and social psychology, 86(1):162-173, 2004.

Spearman, C. "general intelligence," objectively determined and measured. American Journal of Psychology, 15:201-293, 1904.

Spearman, C. The abilities of man, New York: MacMillan, 1927.

U.S. Bureau of Labor Statistics. Dictionary of Occupational Titles. Washington, DC: U.S. Government Printing Office, 4th edition, 1991.

U.S. Bureau of Labor Statistics. Labor Force Characteristics by Race and Ethnicity, 2012. Technical report, Washington, DC: U.S. Government Printing Office, October 2013.

U.S. Bureau of Labor Statistics. Labor Force Characteristics by Race and Ethnicity, 2014. Technical report, Washington, DC: U.S. Government Printing Office, November 2015.

Wonderlic. Wonderlic Personnel Test E Scholastic Level Exam User's Manual. Wonderlic, Inc., 2002. 